\title{
BIOCHEMICAL, PHARMACOLOGICAL, AND HISTOCHEMICAL STUDIES IN NEUROBLASTOMA
}

\author{
BY \\ P. P. ANTHONY, H. M. T. COLES, JOHN PRYSE-DAVIES, and LEONARD SINCLAIR
From Westminster Children's Hospital and the Vincent Square Laboratories of Westminster Hospital
}

(RECEIVED FOR PUBLICATION FEBRUARY 3, 1965)

In recent years there has been some interest in the autonomic effects produced by neural crest tumours and in their biochemical characteristics. Hypertension and diarrhoea have been reported in several cases in which there has also been an excessive excretion of catecholamines, their precursors, or metabolic products (Mason, Hart-Mercer, Millar, Strang, and Wynne, 1957; Isaacs, Medalie, and Politzer, 1959; Voorhess and Gardner, 1961 ; Käser and von Studnitz, 1961; Rosenstein and Engleman, 1963; Marsden, 1963). Most investigators have suggested that these substances have activated the smooth muscle of arterioles or the intestine to produce these effects. However, in other reported cases (Wilkins, 1957; Voorhess and Gardner, 1962) there has been no evidence of excessive secretion of adreno-medullary metabolites to account for these manifestations. Further, Rosenstein and Engleman (1963) and Sourkes, Denton, Murphy, Chavez, and Saint Cyr (1963) recorded cases with no symptoms referable to autonomically innervated structures but with significantly increased secretion of catecholamine derivatives.

This report concerns two cases of metastasizing neuroblastoma and the investigations undertaken upon them. Both had hypertension and in one this was associated with diarrhoea and convulsions. It is thought that the raised blood pressure in one case might be associated with the excessive production of catecholamines by the large tumour mass. In the other patient there is no evidence to indicate that the neuroblastoma produced abnormal amounts of catecholamine-like substances during the period of study or that these were responsible for severe hypertension and intractable diarrhoea.

\section{Methods}

Urinary Excretion of Catecholamines and Metabolites. The combined and individual concentrations of noradrenaline and adrenaline were estimated in 24-hour collections of urine by a fluorometric method based on that of Weil-Malherbe and Bone (1957). 4-hydroxy-3-methoxymandelic acid (HMMA, formerly VMA) was determined by the spectrophotometric method of Pisano, Crout, and Abraham (1962). The concentration of 4-hydroxy-3methoxyphenylacetic acid (homovanillic acid, HVA) was estimated by chromatography according to the method described by Robinson, Ratcliffe, and Smith (1959).

Storage and Treatment of Tumour Tissue. Blocks of each intra-abdominal tumour were removed within 20 minutes of death. Tissue for biochemical, pharmacological, and histochemical investigation was frozen immediately to $-70^{\circ} \mathrm{C}$. using solid carbon dioxide and stored at this temperature until required. Some blocks used for immediate histochemical study were frozen directly on to microtome chucks for use with a cryostat.

Extracts of tumour tissues for biochemical determination of catecholamine concentrations and for pharmacological estimation of pressor substances were prepared by homogenization at $4^{\circ} \mathrm{C}$. in $5 \% \mathrm{w} / \mathrm{v}$ trichloracetic acid using a Potter-Elvehjem hand homogenizer. The extracts for pharmacological study were further washed with diethyl ether to remove excess trichloracetic acid, as recommended by von Euler (1956).

Other tumour blocks were fixed immediately after removal from the body in neutral formalin and Helly's chromate fixative; these were paraffin-embedded and used for histological studies and examined for chromaffin cells.

Determination of Catecholamine Concentrations in Tumour Tissue. Extracts of weighed amounts of tumour tissue prepared as outlined above were investigated by the fluorimetric method used in the urine studies.

Investigation of Pressor Substances in Tumour Tissue. Washed extracts prepared as above were injected into the femoral vein of a dog anaesthetized with pentobarbitone, and arterial blood pressure was recorded directly via a cannula in the femoral artery (Dr. P. Cliffe). The effect of these extracts on the dog's blood pressure was compared with those obtained by injecting a standard noradrenaline solution, trichloracetic acid extracts of other tissues including a phaeochromocytoma, and saline extracts of the tumour and other tissues. 
Histochemical Investigation of Tumour Tissue. Chromate fixation was used in an attempt to demonstrate chromaffin granules. The presence of noradrenaline was sought in $50 \mu$ cryostat sections fixed in formol calcium (Eränkö, 1955). The presence of ganglioneuromatous differentiation was investigated by enzyme histochemical means by studying non-specific esterase and cholinesterase activities in $15 \mu$ cryostat sections, using an azo dye coupling method and a modification of Gomori's acetylthiocholine technique respectively (details given by Pearse, 1960).

As monoamine oxidase plays an important role in the breakdown of adrenaline and noradrenaline in the tissues, the presence of this enzyme was also investigated. Employing the method of Glenner, Burtner, and Brown (1957) and $15 \mu$ cryostat sections of fresh tissue, tryptamine hydrochloride was used as the substrate, and activity was shown by the reduction of Nitro blue tetrazolium (Sigma Chemical Company). The specificity of this method was checked by using control sections preincubated for 30 minutes in $\mathbf{0 . 0 1} \mathrm{M}$ Iproniazid (Marsilid, Roche Products) as a monoamine oxidase inhibitor.

\section{Case Reports}

Case 1. M.V., a male infant, was delivered normally at full term on July 20,1961 , weighing $7 \mathrm{lb}$. (3,175 g.). The mother had not been ill nor had she taken any drugs during pregnancy. The child was admitted to Queen Mary's Hospital for Children, Carshalton, at the age of 1 year suffering from streptococcal tonsillitis and irondeficiency anaemia. Two months later, aged 14 months, he was readmitted with fever and a history of anorexia, vomiting, and increasing pallor. A large, irregular mass was palpable in the left upper quadrant of the abdomen. The $\mathrm{Hb}$ had fallen to $38 \%$, but no abnormal cells were detected in the peripheral blood film.

Shortly after his transfer to Westminster Children's Hospital, when aged 15 months, he developed a unilateral convulsion involving the right side of the face and body. This soon became generalized and continued for an hour despite vigorous anticonvulsant therapy. His blood pressure was noted at this time to be $180 / 110 \mathrm{~mm} . \mathrm{Hg}$. CSF was normal. A bone-marrow aspirate was reported by Dr. J. G. Humble to show the presence of abnormal cells resembling those from a metastatic neuroblastoma. Radiographs (Dr. F. Starer) showed a metastasis in the upper end of the right humerus and at the anterior end of the left eighth rib.

Further clinical features were a large subcutaneous haemangioma of the left buttock and some oedema of the left thigh which extended during four days to involve the left calf and upper portion of the right thigh. A saphenous venogram showed no evidence of obstruction of the left iliac or femoral veins but a lymphangiogram demonstrated dilatation of the lymphatics of the left foot and slow diffusion of dye, indicating lymph stasis in the left leg. Intravenous pyelography showed normal excretion by each kidney. At this time the blood urea was $26 \mathrm{mg} . / 100 \mathrm{ml}$.

After consultation with Dr. K. A. Newton, treatment with cyanocobalamin $1 \mathrm{mg}$. intramuscularly thrice weekly and cyclophosphamide $20 \mathrm{mg}$. intravenously daily was commenced. Initially the tumour extended 3 in. $(7.6 \mathrm{~cm}$.) below the left costal margin in the midclavicular line and to a point in the right upper quadrant $2 \cdot 5$ in. $(6 \cdot 4 \mathrm{~cm}$.) below the costal margin in the midclavicular line. During the first week of treatment it became much smaller, extending only 2 in. $(5 \mathrm{~cm}$.) downwards and across the abdomen only as far as the right mid-clavicular line. Simultaneously the haemangioma of the left buttock shrunk and became necrotic. The blood pressure, however, remained high (190/105 mm.Hg) and the $\mathrm{Hb}$ fell from 92 to $60 \%$.

Treatment with cyclophosphamide was discontinued for one week. Six days after resuming the drug (i.e three weeks after admission) the child passed 8 loose green motions (see Fig. 1), and was pale with cold extremities and feeble, grunting respirations. On the following day the pallor was more marked and there was some abdominal distension with dullness in each flank.

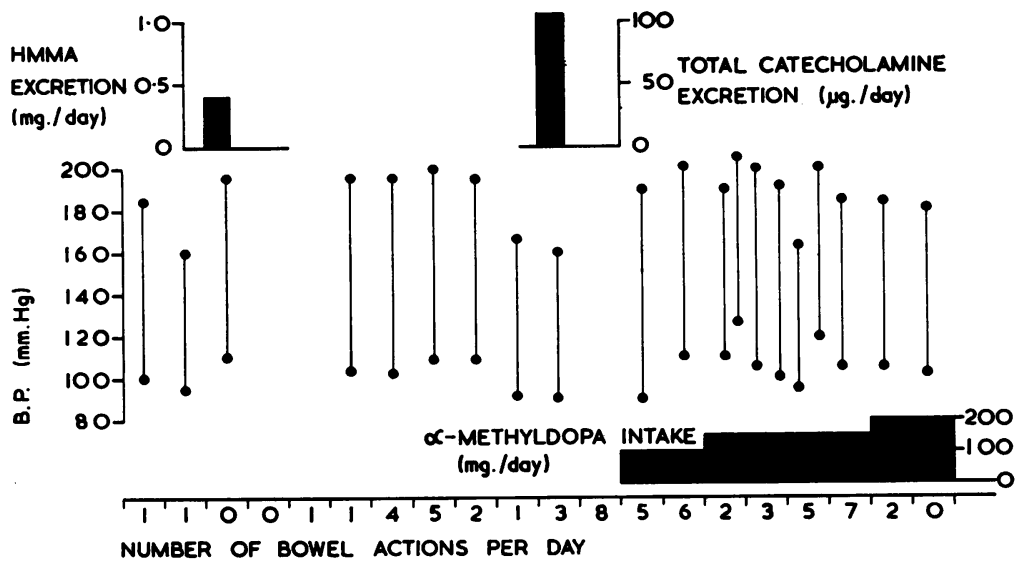

FIG. 1.-Case 1. The absence of an effect of $\alpha$-methyldopa on blood pressure and bowel motility. 
The $\mathrm{Hb}$ had fallen to $40 \%$ and he was thought to have had a retroperitoneal haemorrhage. After transfusion with $220 \mathrm{ml}$. fresh blood the $\mathrm{Hb}$ was only $48 \%$. A further $170 \mathrm{ml}$. was given and the $\mathrm{Hb}$ rose to $74 \%$. A fluctuant swelling now appeared at the anterior end of the left eighth rib. This became smaller during the next three days and the infant's general condition seemed to improve though the hypertension persisted.

In an attempt to reduce dopamine formation from dopa by the tumour and possibly thereby to diminish the diarrhoea as well as to mitigate the hypertension, treatment with $\alpha$-methyldopa at a dosage of $100 \mathrm{mg}$./day was started two days after the onset of the diarrhoea (see Fig. 1). This was increased to $150 \mathrm{mg}$./day two days later and to $200 \mathrm{mg}$./day after a further four days. There was no fall in the blood pressure or decrease in the diarrhoea during the course of this therapy. On the day before death he was comatose and severely dehydrated. Repeated generalized convulsions could not be controlled with phenobarbitone and paraldehyde. Within 20 minutes of death ( 30 days from admission) necropsy was performed and a portion of the tumour removed for estimation of catecholamine content and pharmacological activity.

NeCropsy (Dr. I. M. P. Dawson). The abdomen was protuberant and there was an area of scarring over the left buttock. A large lobulated tumour weighing approximately $670 \mathrm{~g}$. (10\% of the body weight) was found arising from the region of the left adrenal gland, carrying the spleen on the anterior surface, compressing the left lobe of the liver, the upper pole of the left kidney, and surrounding the aorta and the inferior vena cava. The cut surface was necrotic and no adrenal tissue could be identified. The only metastases found were in the right humerus and in the 8th left rib near the costal cartilage. The heart was very enlarged, weighing $54 \mathrm{~g}$. and showing concentric left ventricular hypertrophy. No other cardiovascular changes were found. The kidneys appeared normal. There was evidence of an old retroperitoneal haemorrhage.

Histology. No adrenal tissue could be identified for certain. Much of the tumour was necrotic. The growth that remained consisted of loose sheets of round and oval cells, occasionally forming recognizable rosette structures with conspicuous fibrous and collagen framework. There was no evidence of conversion to ganglioneuroma. In sections of the kidney there were no vascular changes to suggest arterial hypertension.

Case 2. E.S. was 9 years, when in June 1963 he complained of nausea and pain in the right upper quadrant of the abdomen and was admitted to the London Jewish Hospital under the care of Dr. S. B. Dimson. There he was found to have an enlarged liver which was firm and palpable three fingers breadths below the right costal margin. The $\mathrm{Hb}$ was $70 \%$. A bone-marrow biopsy showed evidence of round cell infiltration and a needle aspirate of the liver revealed infiltration with similar cells. An intravenous pyelogram demonstrated a centrally placed mass in the retroperitoneum displacing the right kidney laterally. The diagnosis at the time of transfer to the Westminster Children's Hospital, a month after first admission to hospital, was of an intra-abdominal neuroblastoma with metastasis. Just before this he had developed an evening fever, and his leucocyte count showed a few myelocytes and 2 normoblasts per 100 cells counted.

On admission to Westminster Children's Hospital in early August the liver had increased in size extending to the umbilicus and there was a palpable mass in the left para-aortic area. The blood pressure was $110 / 65 \mathrm{~mm} . \mathrm{Hg}$ and $\mathrm{Hb} 60 \%$. The only investigations of relevance at this time were the urinary excretion of HMMA $(3.7 \mathrm{mg}$./ $24 \mathrm{hr}$.) and hydroxymethyl phenylacetic acid (14 mg./24 hr.). The serum lactic dehydrogenase was 5,000 units and the $\alpha$-hydroxybutyric dehydrogenase 3,500 units (thought in retrospect to be due to tumour necrosis).

Within one week of admission his condition had deteriorated and the $\mathrm{Hb}$ had fallen to $54 \%$. He was transfused with $1,200 \mathrm{ml}$. blood and given mustine hydrochloride $2.0 \mathrm{mg}$. intravenously daily. This induced nausea so was discontinued 2 days later and corticotrophin gel 20 units daily was substituted. During the ensuing week two estimations of 24-hour excretion of urinary catecholamines were $665 \mu \mathrm{g}$. and $590 \mu \mathrm{g}$., respectively. At this time he was normotensive and his clinical condition remained unchanged. By the end of August, however, he showed signs of inferior vena caval obstruction and had collapse/consolidation of the right lower lobe.

One week later his general state was worse, with $\mathrm{Hb}$ of $39 \%$, platelet count of $600 / \mathrm{c}$.mm., and 24-hour catecholamine excretion of $155 \mu \mathrm{g}$. Treatment was changed to prednisone $30 \mathrm{mg}$./day and he was transfused with $600 \mathrm{ml}$. packed cells. He appeared to improve but it was noted on the following day that his blood pressure had risen to $155 / 125 \mathrm{~mm} . \mathrm{Hg}$ and his pulse rate had fallen from 100 to 70 per minute. The size of the abdominal mass had meanwhile increased and the liver had enlarged, extending to below the umbilicus.

Next morning the heart rate suddenly increased to 136 and he rapidly lapsed into unconsciousness, with frothing at the mouth and incontinence of urine and faeces. There was generalized muscular hypotonia and hyporeflexia, with conjugate deviation of the eyes to the right. The CSF pressure was over $300 \mathrm{~mm}$. with a protein content of $40 \mathrm{mg} . / 100 \mathrm{ml}$. There were 3 lymphocytes and more than 600 erythrocytes/c.mm. No abnormal cells were detected. The patient was treated with intravenous phentolamine and oral guanethidine but the hypertension and tachycardia persisted. The $\mathrm{Hb}$ fell to $28 \%$ and he was again transfused with $1,200 \mathrm{ml}$. packed cells. He continued to deteriorate and died at the end of September, less than four months from the onset of his illness.

Necropsy (Dr. J. Pryse-Davies). A preliminary necropsy was performed within 20 minutes of death in order to remove as freshly as possible specimens of the tumour from the abdomen for storage at $-70^{\circ} \mathrm{C}$. The necropsy was completed 10 hours later. 
TABLE

COMPARISON OF CLINICAL FEATURES AND INVESTIGATIONS ON EACH PATIENT

\begin{tabular}{|c|c|c|c|c|c|c|c|c|c|}
\hline & & & & & & & Case 1 & \multicolumn{2}{|c|}{ Case 2} \\
\hline $\begin{array}{l}\text { Autonomic effects present } \\
\text { Response to phentolamine } \\
\text { Response to } \alpha \text {-methyldopa }\end{array}$ & $\begin{array}{l}\cdots \\
\cdots \\
\cdots\end{array}$ & $\begin{array}{l}\cdots \\
\cdots\end{array}$ & $\begin{array}{l}\cdots \\
\cdots\end{array}$ & $\cdots$ & $\begin{array}{l}\cdots \\
\cdots\end{array}$ & $\begin{array}{l}\cdots \\
\cdots \\
\cdots\end{array}$ & $\begin{array}{c}\text { Tachycardia, hypertension, } \\
\text { and diarrhoea } \\
\text { Fall in blood pressure } \\
\text { None }\end{array}$ & \multicolumn{2}{|c|}{$\begin{array}{l}\text { Tachycardia, hypertension } \\
\text { No change }\end{array}$} \\
\hline & & & & & & & $\begin{array}{l}\text { In presence of } \\
\text { hypertension }\end{array}$ & $\begin{array}{c}\text { Before onset of } \\
\text { hypertension }\end{array}$ & $\begin{array}{l}\text { After onset of } \\
\text { hypertension }\end{array}$ \\
\hline \multicolumn{6}{|c|}{ 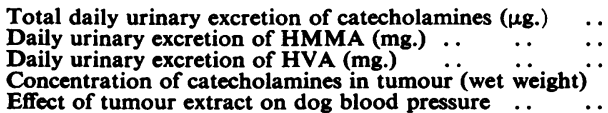 } & $\begin{array}{l}\ldots \\
\ldots \\
\ldots \\
\ldots\end{array}$ & $\begin{array}{c}103 \\
0.4 \text { and } 2 \cdot 3 \\
\overline{N i l} \\
\text { Nil }\end{array}$ & $\begin{array}{c}665 \text { and } 590 \\
\text { Z } \\
\text { - }\end{array}$ & $\begin{array}{c}340 \text { and } 142 \\
3 \cdot 7 \\
14 \cdot 0 \\
3 \cdot 0 \mu g . / g . \\
\text { Rise }\end{array}$ \\
\hline
\end{tabular}

The body was that of a wasted child with a protuberant abdomen due to a large retroperitoneal mass which pushed the liver forwards and was closely applied to the posterior wall of the abdomen enclosing the aorta and inferior vena cava. The left kidney was not affected but the right kidney was distorted, the pelvis being invaded but the cortex uninvolved though stretched around the growth. The tumour weighed $730 \mathrm{~g}$. and measured 15 $\mathrm{cm}$. in maximum diameter. The cut surface was reddishpink in colour divided by some fibrous septa. Since the right adrenal gland was not identified it was presumed that the tumour had arisen from the right adrenal medulla or possibly from ganglionic tissue in this region. Metastases were present in the right parietal and visceral pleurae, in the pancreas, sternal, and femoral bonemarrow, in lymph nodes at the aortic arch and near the porta hepatis, in the skull at the lateral point of the greater wing of the right sphenoid bone and also the left parietal bone just lateral to the vertex.

Histology. The tumour was composed of small round cells with scanty cytoplasm arranged in sheets but showing a few areas of classical rosette formation. There was a fair amount of necrosis and local haemorrhage. No evidence of hypertensive change was found in sections of the kidneys.

\section{Investigations}

Response to Phentolamine. In Case 1 this was tested measuring systolic pressures only. The baseline level was $220 \mathrm{mim} . \mathrm{Hg}$. One minute after $1 \mathrm{mg}$. of the drug intravenously it fell to $130 \mathrm{~mm} . \mathrm{Hg}$, rising again gradually to $155 \mathrm{~mm} . \mathrm{Hg}$. The response appears to be significant by the criteria of Soffer (1954).

In Case 2 there was no response to intravenous phentolamine $2 \mathrm{mg}$. initially, then $2 \mathrm{mg}$. hourly for 10 hours, and $3 \mathrm{mg}$. hourly for a further 5 hours. The blood pressure remained approximately $155 / 125 \mathrm{~mm} . \mathrm{Hg}$ throughout.

Excretion of Adreno-medullary Metabolites. These are shown in the Table. In Case 1 the only complete 24-hour urine collection contained $103 \mu \mathrm{g}$. catecholamines. Few figures for the normal values at this age are available. Sourkes et al. (1963), using similar methods, give the range for combined adrenaline and noradrenaline excretion as 3 to $115 \mu \mathrm{g} . / 24 \mathrm{hr}$. with a daily mean of $31 \mu \mathrm{g}$. The subject with the highest excretion in this series was a 13-month-old boy with supraventricular tachycardia. Voorhess and Gardner (1960) give a mean figure of less than $15 \mu \mathrm{g} . / 24 \mathrm{hr}$. The excretion of catecholamines was much increased in Case 2 . Initially they were 665, 590, and $340 \mu \mathrm{g}$. $/ 24 \mathrm{hr}$. and fell to $142 \mu \mathrm{g}$. terminally. The excretion of HMMA was within the normal range for each patient (M. Sandler and C. R. J. Ruthven, 1964, personal communication) and that of HVA was increased in Case $2(14 \mu \mathrm{g} . / 24 \mathrm{hr}$.).

Response to $\alpha$-Methyldopa. This agent was tried in Case 1 (see Fig. 1). The dosage was increased from $100 \mathrm{mg}$. to $200 \mathrm{mg}$. over seven days. As can be seen there was no alteration in systolic blood pressure or amelioration of the diarrhoea. The drug was not used in Case 2.

Biochemical and Pharmacological Investigations of Tumour Tissues. An extract of the tumour in Case 1 was examined for the presence of catecholamine-like substances by Mr. C. R. J. Ruthven but none could be detected in stored material investigated 6 weeks after death. A similar extract from Case 2 was examined in the Vincent Square Laboratories of Westminster Hospital by Mr. B. Morris using the fluorimetric method. In this a total catecholamine concentration of $3.0 \mu \mathrm{g} . / \mathrm{g}$. wet tissue was found $(2.4 \mu \mathrm{g}$. noradrenaline and $0.6 \mu \mathrm{g}$. adrenaline). The tumour weighed $730 \mathrm{~g}$. Assuming a uniform distribution in the growth the total noradrenaline content was thus $1,750 \mu \mathrm{g}$. and that of adrenaline $438 \mu \mathrm{g}$.

The effects of extracts on the blood pressure of a dog were observed in each case. The tissues from the tumours had been stored for 6 months and 6 weeks, respectively. A similar extract was made of mouse kidney and a phaeochromocytoma; saline extracts of the tumour and mouse tissues were also examined. Each extract from Case 1 caused no significant rise of blood pressure when injected into an anaesthetized dog (Fig. 2a). The extract from the phaeochromocytoma (Fig. 3) and a standard noradrenaline solution (Fig. 2b) caused a sustained rise in pressure, while the mouse kidney and saline extracts of the tumour caused no alteration.

The injection of tumour extract from Case 2 produced a significant rise in femoral artery pressure which, by comparison with noradrenaline standards, indicated a 


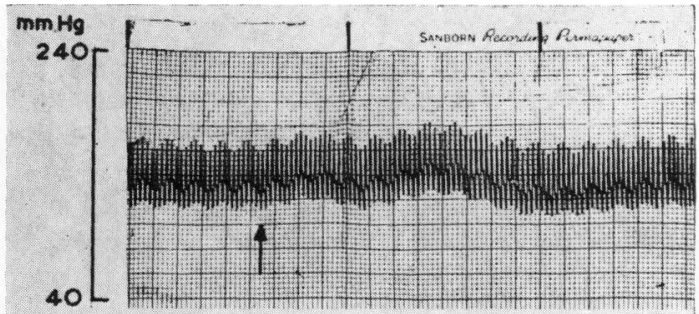

(a)

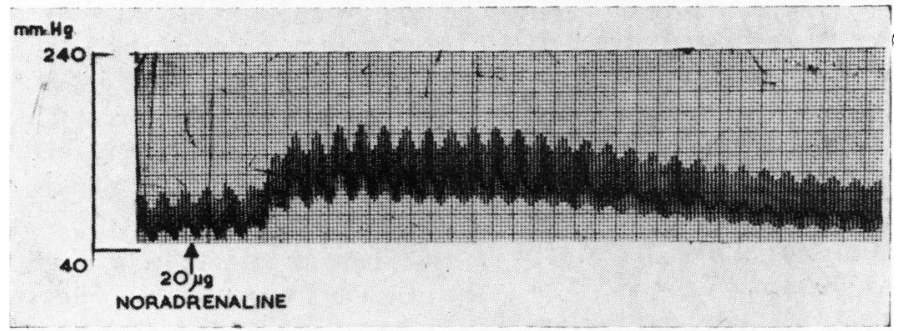

(b)

FIG. 2.-Effect on the femoral artery pressure of an anaesthetized dog of injecting (a) extract of tumour from Case 1- no effect (marker at top of recording equals 4 seconds); (b) $20 \mu \mathrm{g}$. noradrenaline.

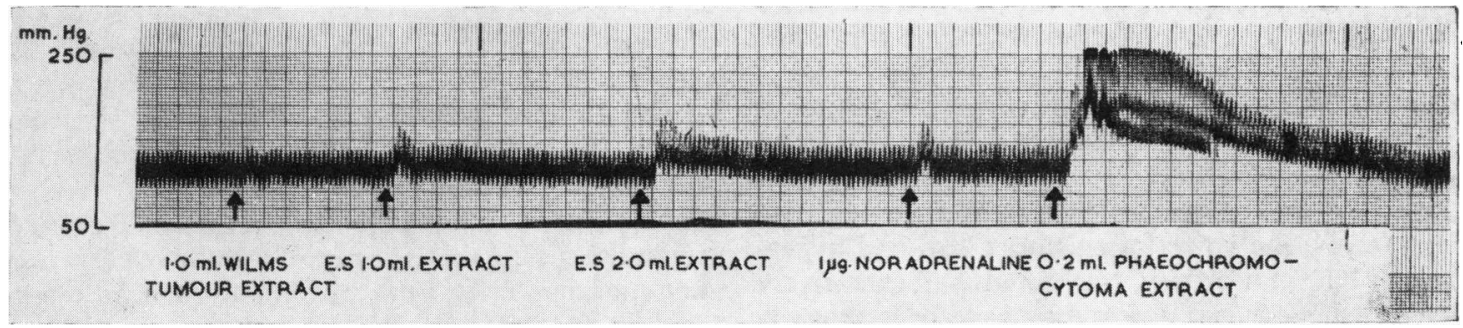

FIG. 3.-Effect of injecting extract of a Wilm's tumour, extract from tumour of Case 2 (E.S.), noradrenaline, and extract of a phaeochromocytoma on the femoral artery pressure of an anaesthetized dog. Marker at top of recording equals 20 seconds.

concentration in the tumour of 4 to $5 \mu \mathrm{g}$./g. weight of tumour. The phaeochromocytoma extract was still potent after storage of the tissue in the deep freeze for 7 months while an extract from a Wilm's tumour metastasis in liver caused no effect (Fig. 3).

Histochemistry of Tumour Tissue. Tissue fixed in Helly's fluid from both tumours did not show any evidence of chromaffin granules. Fluorescent microscopic techniques for noradrenaline were also negative in both cases. There was no evidence of selective nonspecific esterase activity or of cholinesterase activity in either tumour. Monoamine oxidase activity was clearly demonstrated in freshly taken blocks from tumour in Case 2 in the cytoplasm of the small neoplastic cells throughout the sections: staining was completely inhibited in sections pre-incubated in iproniazid (Marsilid). Unfortunately this enzyme was not studied in tumour tissue from Case 1 at the time of removal from the body; no activity was detectable in blocks stored for
10 months at $-70^{\circ} \mathrm{C}$. During this period we have also investigated monoamine oxidase activity by this method in two Wilm's tumours with negative results.

\section{Discussion}

The coincidence of diarrhoea, hypertension, and convulsions is quite uncommon in cases of adrenal neuroblastoma. In a recent review of the subject, Rosenstein and Engleman (1963) recorded but one instance in a series of 68 patients seen at Johns Hopkins Hospital between 1925 and $1962 . \quad$ Voorhess and Gardner (1961) had previously recorded one case and in the same year Smellie and Sandler described these manifestations in a child with a secreting intrathoracic ganglioneuroma. In the latter case, after the tumour had been removed, the diarrhoea subsided. This was also the result in a case reported by Stickler, Hallenbeck, and Flock 
(1960), but in their patient it is of particular interest to note that, despite the relief of symptoms, the urinary excretion of excessive quantities of catecholamines persisted.

In all these patients the evidence indicated that there was an increased production of adrenal medullary metabolites. This was not so in our first case. The urinary excretion of catecholamines was thought to be at the upper limit of normal and that of HMMA within the normal range (M. Sandler and C. R. J. Ruthven, 1964, personal communication). The symptoms referable to the autonomic nervous system were not relieved by the administration of $\alpha$-methyldopa; an extract of the tumour examined post mortem contained no catecholamines and had no effect on the blood pressure of an anaesthetized dog. Although the phentolamine test was positive, there is some doubt about the validity of this type of investigation (Pickering, 1955).

The accumulated evidence thus points to the conclusion that the hypertension and diarrhoea were not due to one of the series of compounds formed during the production or degradation of adrenaline and noradrenaline. Some of the points about these investigations, however, require more critical discussion.

Only a proportion of patients with neuroblastoma excrete excessive catecholamines. Bell (1963) and Voorhess and Gardner (1962) report several with normal or low excretions. In particular one case recorded by the latter investigators also had hypertension but, at necropsy, the growth had extensively invaded the kidneys, and it may have been that the urinary excretion of catecholamines was limited or the hypertension was nephrogenic. In Case 1 the urinary excretion of HMMA and catecholamines was not measured in relation to creatinine excretion, but there was never any evidence to indicate that renal function was sufficiently impaired to affect the excretion of monoamines significantly. The blood urea remained normal throughout except terminally, intravenous pyelography showed good elimination of the contrast material, and there was no post-mortem evidence of renal involvement.

As $\alpha$-methyldopa is a competitive inhibitor of decarboxylase in tissues producing monoamines, it should theoretically have limited the production of dopamine from dopa and thus have blocked adrenaline, noradrenaline, and 5-hydroxytryptamine formation in the tumour. The lack of response could have been due to any of the following factors.

(1) The symptoms were not caused by these agents.

(2) The dose of $\alpha$-methyldopa was insufficient.

(3) The tumour tissue was not penetrated by adequate concentrations of the drug.
It is impossible to be certain which of these was operative but, as regards the third, the tumour was very vascular and the blood supply to those parts that were metabolically active must have been good.

It may be, of course, that the agent produced by the tumour in Case 1 was not a catecholamine derivative. It could, for example, have been one of the kinins. An agent of this type may have been released by enzyme activators, such as proteases, produced by the tumour. A mechanism of this type might account for the unexplained diarrhoea reported by other workers, and further investigations on these lines may yet prove rewarding. It should be noted here that Birkenhäger (1963) has already reported a neuroblastoma in an adult male who had excessive excretion of 5-hydroxytryptophan derivatives in the urine.

There appears to be no doubt that the hypertension in Case 2 was related to the secretion of adrenergic agents from a tumour which was large and contained a significant amount of catecholamines, though less than some (Bell, 1963). It is also true that when the patient was first recognized to have a large growth with excessive catecholamine excretion his blood pressure was normal and the hypertension was sudden in onset. The rise in blood pressure occurred over two days, during which time he developed signs suggesting a cerebral metastasis. It appears that this was due either to a sudden secretion of catecholamine-like substances from the tumour tissue, or to the release of metabolically active metastasizing cells from the main tumour mass. This point should also be considered in relation to Case 1 where, though the primary tumour may not have been producing an active agent at the time of death, several of the metastases may have been doing so. Thus their pharmacological activity may have been overlooked in the post-mortem investigations.

The various factors discussed above in relation to the causes of hypertension and diarrhoea in these two children indicate the need for investigating the patient and the tumour by as many relevant methods as possible. Although the diagnosis of neuroblastoma may usually be made by routine clinical and pathological methods, a great deal more information about functional effects can be obtained by using the biochemical, pharmacological, and histochemical techniques reported in this paper. Enzyme histochemical studies of these tumours might well be developed further. Non-specific esterase and acetylcholinesterase should give an indication of ganglioneuromatous differentiation as recently suggested in work on carotid body tumours (PryseDavies, Dawson, and Westbury, 1964). Monoamine oxidase activity may also be of use in character- 
izing neuroblastoma cells, and it is interesting to speculate on the relation between catecholamine production and monoamine oxidase concentrations in such tumours.

\section{Summary}

It has been assumed that the autonomic effects induced by neuroblastomata are always due to the production of catecholamine compounds. Two cases are reported with details of biochemical, pharmacological, and histochemical investigations. In one there was hypertension, and evidence suggested that this was due to the release of adrenaline and noradrenaline. In the other patient, who suffered both hypertension and diarrhoea, there was no evidence to indicate that the tumour was associated with excessive catecholamine activity, and it is postulated that another agent, not a catecholamine derivative, may have been produced by the tumour.

We wish to thank Dr. J. G. Humble, Dr. K. A. Newton, Mr. J. C. Ruthven, Dr. Merton Sandler, and Dr. J. H. Wilkinson for their co-operation, Dr. Ian Dawson for his constructive criticism, Dr. Percy Cliffe and the Department of Clinical Measurement, Westminster Hospital for invaluable help in the pharmacological work, and Dr. Peter Hansell and the Department of Medical Photography, Westminster Hospital for the preparation of the photographs. One of us (J.P-D) was in receipt of a grant from the British Empire Cancer Campaign.

\section{REFERENCES}

Bell, M. (1963). The clinical chemistry of neuroblastomas. In West-European Symposia on Clinical Chemistry, Vol. 2, ed. H. Varley and A. H. Gowenlock, p. 82. Elsevier, Amsterdam, London, and New York.

Birkenhäger, J. C. (1963). Metastasizing neuroblastoma with excretion of 5-hydroxyindoleacetic acid, serotonin and 5-hydroxytryptophan. Acta med. scand., 174, 621

Eränkö, O. (1955). Distribution of adrenaline and noradrenaline in the adrenal medulla. Nature (Lond.), 175, 88.

Euler, U. S. von (1956). Noradrenaline: Chemistry, Physiology, Pharmacology and Clinical Aspects, 1st ed., p. 62. Thomas, Springfield, Illinois.
Glenner, G. C., Burtner, H. J., and Brown, G. W., Jr. (1957). The histochemical demonstration of monoamine oxidase activity by tetrazolium salts. J. Histochem. Cytochem., 5, 591.

Isaacs, H., Medalie, M., and Politzer, W. M. (1959). Noradrenalinesecreting neuroblastomata. Brit. med. J., 1, 401.

Käser, H., and von Studnitz, W. (1961). Urine of children with sympathetic tumours. The excretion of 3-methoxy-4-hydroxymandelic acid. Amer. J. Dis. Child., 102, 199.

Marsden, H. B. (1963). Clinical and pathological features of neuroblastoma. In West European Symposia on Clinical Chemistry, Vol. 2, ed. H. Varley and A. H. Gowenlock, p. 71. Elsevier, Amsterdam, London, and New York.

Mason, G. A., Hart-Mercer, J., Millar, E. J., Strang, L. B., and Wynne, N. A. (1957). Adrenaline-secreting neuroblastoma in an infant. Lancet, 2, 322.

Pearse, A. G. E. (1960). Histochemistry: Theoretical and Applied, 2nd ed. Churchill, London.

Pickering, G. W. (1955). High Blood Pressure, p. 404. Churchill, London.

Pisano, J. J., Crout, J. R., and Abraham, D. (1962). Determination of 3-methoxy-4-hydroxymandelic acid in urine. Clin. chim. Acta, 7, 285.

Pryse-Davies, J., Dawson, I. M. P., and Westbury, G. (1964). Some morphologic, histochemical, and chemical observations on chemodectomas and the normal carotid body, including a study of the chromaffin reaction and possible ganglion cell elements. Cancer (Philad.), 17, 185.

Robinson, R., Ratcliffe, J., and Smith, P. (1959). A screening test for phaeochromocytoma. J. clin. Path., 12, 541.

Rosenstein, B. J., and Engleman, K. (1963). Diarrhea in a child with a catecholamine-secreting ganglioneuroma: case report and review of the literature. J. Pediat., 63, 217.

Smellie, J. M., and Sandler, M. (1961). Secreting intrathoracic ganglioneuroma. Proc. roy. Soc. Med., 54, 327.

Soffer, A. (1954). Regitine and benodaine in the diagnosis of phoechromocytoma. Med. Clin. N. Amer., 38, 375.

Sourkes, T. L., Denton, R. L., Murphy, G. F., Chavez, B., and Saint Cyr, S. (1963). The excretion of dihydroxyphenylalanine, dopamine and dihydroxyphenylacetic acid in neuroblastoma. Pediatrics, 31, 660.

Stickler, G. B , Hallenbeck, G. A., and Flock, E. V. (1960). Ganglioneuroblastoma associated with increased excretion of catecholamines. Amer. J. Dis. Child., 100, 634.

Voorhess, M. L., and Gardner, L. I. (1960). Catecholamine metabolism in neuroblastomas. Lancet, 2, 651 .

, and (1961). Urinary excretion of norepinephrine, epinephrine and 3-methoxy-4-hydroxymandelic acid by children with neuroblastoma. J. clin. Endocr., 21, 321.

, and - (1962). Studies of catecholamine excretion by children with neural tumors. ibid., 22, 126.

Weil-Malherbe, H., and Bone, A. D. (1957). The estimation of catecholamines in urine by a chemical method. J. clin. Path., 10, 138.

Wilkins, L. (1957). The Diagnosis and Treatment of Endocrine Disorders in Childhood and Adolescence, 2nd ed., p. 254. Thomas, Springfield, Illinois. 